\title{
Optimisation of Copper Oxide Impregnation on Carbonised Oil Palm Empty Fruit Bunch for Nitric Oxide Removal using Response Surface Methodology
}

\author{
Norhidayah Ahmad ${ }^{1}$, Sing Hung Yong ${ }^{1}$, Naimah Ibrahim $^{1 *}$, Umi Fazara Md Ali ${ }^{1}$, Fahmi \\ Muhammad Ridwan ${ }^{1}$ and Razi Ahmad ${ }^{1}$ \\ ${ }^{1}$ School of Environmental Engineering, Universiti Malaysia Perlis, 02600 Arau, Perlis, Malaysia
}

\begin{abstract}
Oil palm empty fruit bunch (EFB) was successfully modified with phosphoric acid hydration followed by impregnation with copper oxide $(\mathrm{CuO})$ to synthesize $\mathrm{CuO}$ modified catalytic carbon $(\mathrm{CuO} / \mathrm{EFBC})$ for low-temperature removal of nitric oxide (NO) from gas streams. $\mathrm{CuO}$ impregnation was optimised through response surface methodology (RSM) using Box-Behnken Design (BBD) in terms of metal loading (5-20\%), sintering temperature $\left(200-800^{\circ} \mathrm{C}\right)$ and sintering time $(2-6$ hours). The model response for the variables was NO adsorption capacity, which was obtained from an up-flow column adsorption experiment with $100 \mathrm{~mL} / \mathrm{min}$ flow of $500 \mathrm{ppm} \mathrm{NO} / \mathrm{He}$ at different operating conditions. The optimum operating variables suggested by the model were $20 \%$ metal loading, $200^{\circ} \mathrm{C}$ sintering temperature and 6 hours sintering time. A good agreement $\left(\mathrm{R}^{2}=0.9625\right)$ was achieved between the experimental data and model prediction. ANOVA analysis indicated that the model terms (metal loading and sintering temperature) are significant (Prob. $>$ F less than 0.05 ).
\end{abstract}

\section{Introduction}

Nitric oxides $\left(\mathrm{NO}_{\mathrm{x}}\right)$ is one of the major air pollutants mainly contributed from fuel combustion process in stationary and mobile sources [1-2]. $\mathrm{NO}_{\mathrm{x}}$ causes severe environmental problems such as photochemical smog, and acid rain which are harmful to both human and environment [3]. One of the widely used methods to control $\mathrm{NO}_{\mathrm{x}}$ is selective catalytic reduction (SCR). SCR process involves the use of catalyst system like vanadium supported on titanium oxide with external reducing agents such as $\mathrm{NH}_{3}$ or urea to convert $\mathrm{NO}_{x}$ into $\mathrm{N}_{2}$ and $\mathrm{H}_{2} \mathrm{O}$. The catalytic reaction is effective at temperature higher than $350^{\circ} \mathrm{C}$.

The use of carbonaceous materials derived from agricultural wastes in SCR of $\mathrm{NO}_{\mathrm{x}}$ is an alternative technique that allows low temperature $\left(100-300^{\circ} \mathrm{C}\right)$ application. Extensive study on carbonaceous materials for NO reduction is possibly due to the material abundance and cost. Besides, carbonaceous material derived from agriculture waste shows

\footnotetext{
* Corresponding author: naimah@unimap.edu.my
} 
high porosity and surface area which are beneficial for removal of $\mathrm{NO}_{\mathrm{x}}$ [4]. Such materials include olive stone [5], rice husk [6], orange skin [7], palm shell [2], plum stone [8], and coconut shell [9]. In Malaysia, oil palm biomass including empty fuit bunch (EFB) is available in abundance. Hence it is very useful and economical to utilize EFB as the carbon precursor in this study.

Impregnation of additives e.g. metal catalyst on the carbonaceous material's surface is another step to enhance $\mathrm{NO}_{x}$ reduction. Copper oxide $(\mathrm{CuO})$ for example was used in many studies including our previous work as it is inexpensive and exhibits high reactivity towards NO reduction [10-12]. The variables chosen in the process of $\mathrm{CuO}$ impregnation onto the carbonised EFB (CuO/EFBC) may affect the effectiveness of $\mathrm{NO}_{\mathrm{x}}$ reduction, therefore, this study aims to optimise $\mathrm{CuO}$ impregnation using response surface method, specifically using Box-Behnken design (BBD). In this independent quadratic design, the treatment combinations are at the midpoints of edges of the process space and at the centre. $\mathrm{BBD}$ is favourable because less number of experimental runs is required [4].

\section{Experimental}

\subsection{Material preparation}

Fibrous oil palm EFB sample was collected from United Oil Palm Mill Sdn. Bhd., Nibong Tebal, Malaysia. The collected EFB fibre was washed with water and dried in oven at $110^{\circ} \mathrm{C}$ for $24 \mathrm{~h}$. The EFB was first carbonized and activated using one-stage chemical activation with phosphoric acid $\left(\mathrm{H}_{3} \mathrm{PO}_{4}\right)$ at $1: 1(\mathrm{w} / \mathrm{v})$ ratio and heated in the furnace for 24 $\mathrm{h}$ at $400^{\circ} \mathrm{C}$ to create pores, as described in previous work [10]. The heated EFB was then washed with distilled water to remove the remaining acid. Each $10 \mathrm{~g}$ of the carbonized material (EFBC) was further impregnated with $\mathrm{CuO}$ catalyst at varied loadings. Metal loading was as suggested by RSM based on minimum and maximum set of values obtained from the literature review. Then, $50 \mathrm{~mL}$ of distilled water was added to the mixture of $\mathrm{EFBC}$ and $\mathrm{CuO}$ and stirred with the magnetic stir bar for 4 hours. The mixture was then heated by double boiling method at $70^{\circ} \mathrm{C}$ until the liquid part evaporated. After dried, the samples were sintered in the furnace at temperature and time suggested by RSM based on fixed minimum and maximum set of values. Finally, the resulting sample of $\mathrm{CuO} / \mathrm{EFBC}$ was weighed and sieved to gain average particles sizes in the range of $0.5-1 \mathrm{~mm}$ for further testing.

\subsection{NO removal experiment}

NO adsorption experiment was explained in detailed in the previous work [10], except that the operating parameters i.e. sample loading, gas concentration and reaction temperature were changed to $5 \mathrm{~g}$ of $\mathrm{CuO} / \mathrm{EFBC}, 500 \mathrm{ppm} \mathrm{NO} / \mathrm{He}$ and $200^{\circ} \mathrm{C}$. The total gas flow rate was maintained at $100 \mathrm{~mL} / \mathrm{min}$, but passed through the packed bed reactor in an up-flow manner. Outlet NO concentration was measured by $\mathrm{NO}-\mathrm{NO}_{2}$ analyser (TESTO 340, Germany) at the end of the system for one hour. Differential amount of NO removed from gas stream and adsorbed by the $\mathrm{CuO} / \mathrm{EFBC}$ catalyst system was measured in an experimental set-up shown in the same previous work. For the model response, NO removed from the gas streams or adsorbed by $\mathrm{CuO} / \mathrm{EFBC}$ was calculated by the following equations (Eqs. 1 and 2). In this case, $q$ was calculated using experimental NO concentration data from breakthrough curve at time equivalent, $t_{t}$, which can be obtained by integrating the fraction of $\mathrm{NO}$ removed $\left(1-C / C_{\mathrm{o}}\right)$ per minute using trapezoidal method (Eq.1) [2]. 


$$
\begin{aligned}
& t_{t}=\int_{0}^{\infty} 1-\frac{c}{C_{o}} \\
& q=\frac{C_{\mathrm{NO}} Q_{\mathrm{f}} t_{\mathrm{t}} y_{\mathrm{f}}}{m_{\mathrm{c}}}
\end{aligned}
$$

where $q$ is adsorption capacity of $\mathrm{NO}(\mathrm{mg} / \mathrm{g}), C_{\mathrm{NO}}$ is $\mathrm{NO}$ concentration $(\mathrm{mg} / \mathrm{L}), Q_{f}$ is gas flow rate $(\mathrm{L} / \mathrm{min}), t_{t}$ is time equivalent $(\mathrm{min})$ calculated using Eq. 1, $y_{\mathrm{f}}$ is mole fraction of $\mathrm{NO}$, and $m_{c}$ is mass of adsorbent $(\mathrm{g})$.

\subsection{Design of Experiment}

\subsubsection{Experimental design}

$\mathrm{CuO}$ impregnation variables studied include (i) $\mathrm{x}_{1}$, metal loading; (ii) $\mathrm{x}_{2}$, sintering temperature and (iii) $\mathrm{x}_{3}$, sintering time, while the performance indicator or response is the NO adsorption capacity. The minimum (-1), centre (0) and maximum (1) set of values for the three variables given in Table 1 were selected based on literature and preliminary studies. A total of seventeen (17) experimental runs were suggested by RSM. The sequence of experimental run was randomized in order to minimize errors due to uncontrollable factors.

\begin{tabular}{|c|c|c|c|c|c|}
\hline \multicolumn{3}{|c|}{ Variables } & \multicolumn{3}{|c|}{ Coded variables level } \\
\hline & Code & Unit & -1 & 0 & 1 \\
\hline Metal loading & $\mathrm{x}_{1}$ & $\%$ & 5 & 12.5 & 20 \\
\hline Sintering temperature & $\mathrm{x}_{2}$ & ${ }^{\circ} \mathrm{C}$ & 200 & 400 & 800 \\
\hline Sintering time & $\mathrm{x}_{3}$ & hour & 2 & 4 & 6 \\
\hline
\end{tabular}

Table 1. Independent variables and their coded levels for the Box Behnken Design.

\subsubsection{Model development}

The response variables (i.e. NO adsorption capacity) obtained from the seventeen experimental runs were used to develop an empirical, quadratic model that correlates the response to the three factors, by using a second degree polynomial equation [13] given by Eq. 3.

$$
\begin{aligned}
& Y=\beta_{0}+\beta_{1} x_{1}+\beta_{2} x_{2}+\beta_{3} x_{3}+\beta_{12} x_{1} x_{2}+\beta_{13} x_{1} x_{3}+\beta_{23} x_{2} x_{3}+\beta_{11} x_{1}{ }^{2}+\beta_{22} x_{2}{ }^{2}+ \\
& \beta_{33} x_{3}{ }^{2}+\varepsilon
\end{aligned}
$$

where $\mathrm{Y}$ is the predicted response, $\beta_{0}$ is model constant, $x_{1}, x_{2}$, and $x_{3}$ are independent variables, $\beta_{1}, \beta_{2}$ and $\beta_{3}$ are linear coefficients, $\beta_{12}, \beta_{13}$ and $\beta_{23}$ are cross-product coefficients, $\beta_{11}, \beta_{22}$ and $\beta_{33}$ are the quadratic coefficients and $\varepsilon$ is the statistical error term. 


\subsubsection{Statistical and graphical analysis}

The correlation coefficient value $\left(\mathrm{R}^{2}\right)$, Fisher value (F-value) and probability (P-value) from analysis of variance (ANOVA) was used to evaluate the quality and significance of the model and model terms. Graphs were employed to analyse the combined effect of factors on the response using $3 \mathrm{D}$ plot and to analyse the predicted response variables versus experimental value.

\subsubsection{Model optimisation and validation}

Model optimisation was done to determine the optimum operating conditions for the process variables under consideration. To achieve this, goals were set based on the combined effect of factors on responses. Model validation was carried out by conducting $\mathrm{NO}$ removal experiment using $\mathrm{CuO} / \mathrm{EFBC}$, prepared based on optimum operating conditions suggested by the model. The experimental values (NO adsorption capacity) obtained were compared with the model predicted values.

\section{Results and discussions}

\subsection{Development of model for optimisation of $\mathrm{CuO}$ impregnation}

The response in term of NO adsorption capacity obtained from the seventeen experimental runs carried out according to operating variables suggested by RSM is presented in Table 2, together with the experimental design variables mentioned in Section 2.3.1.

Based on the data in Table 2, a quadratic model was developed using RSM. The final empirical model for NO adsorption was then obtained in terms of coded factors (parameters) as presented in Eq. 4.

$$
\begin{aligned}
& \mathrm{Y}_{1}=6.09672 \times 10^{-3}-1.64944 \times 10^{-3} \mathrm{x}_{1}+2.62639 \times 10^{-3} \mathrm{x}_{2}-5.67000 \times 10^{-4} \mathrm{x}_{3}-1.55556 \mathrm{x} \\
& 10^{-3} \mathrm{x}_{1} \mathrm{x}_{2}+1.01667 \mathrm{x}_{1} \mathrm{x}_{3}-4.79167 \times 10^{-7} \mathrm{x}_{2} \mathrm{x}_{3}+9.39556 \times 10^{-6} \mathrm{x}_{1}{ }^{2}+8.72222 \times 10^{-10} \mathrm{x}_{2}{ }^{2}+ \\
& 8.9 \times 10^{-5} \mathrm{x}_{3}^{2}
\end{aligned}
$$

The fitness of the model developed was evaluated based on the correlation coefficient value $\left(\mathrm{R}^{2}\right)$ obtained from linear model extrapolation showed in Fig. 1. The $\mathrm{R}^{2}$ value closer to unity is desirable as an indication that predicted values are closer to the actual values [14]. The $\mathrm{R}^{2}$ value is relatively high at $\mathrm{R}^{2}=0.9625$, indicating that there is good agreement between the adsorption capacity from experimental data and model prediction.

\subsection{Statistical and graphical analysis of model}

The adequacy of the model was further evaluated through analysis of variance (ANOVA). Table 3 shows the analysis done on the quadratic model for $\mathrm{NO}$ adsorption capacity $\left(\mathrm{Y}_{1}\right)$. Model terms, $\mathrm{x}_{1}, \mathrm{x}_{2}, \mathrm{x}_{3}$ refer to metal loading, sintering temperature and sintering time. 
Table 2. Experimental design matrix for optimisation of $\mathrm{CuO}$ impregnation onto EFBC.

\begin{tabular}{ccccc}
\hline & \multicolumn{3}{c}{ Variables } & Response \\
\cline { 2 - 5 } $\begin{array}{c}\text { Experimental } \\
\text { Run }\end{array}$ & $\begin{array}{c}\mathrm{X} 1 \\
\text { Metal } \\
\text { loading } \\
(\%)\end{array}$ & $\begin{array}{c}\mathrm{X}_{2} \\
\text { Sintering } \\
\text { temperature } \\
\left({ }^{\circ} \mathrm{C}\right)\end{array}$ & $\begin{array}{c}\mathrm{X}_{3} \\
\text { Sintering } \\
\text { time } \\
(\mathrm{hr})\end{array}$ & $\begin{array}{c}\mathrm{Y} \\
\text { Adsorption Capacity } \\
(\mathrm{mg} / \mathrm{g})\end{array}$ \\
\hline 1 & 5.0 & 200 & 4 & 0.00504 \\
2 & 20.0 & 200 & 4 & 0.00614 \\
3 & 5.0 & 800 & 4 & 0.00531 \\
4 & 20.0 & 800 & 4 & 0.00501 \\
5 & 5.0 & 500 & 2 & 0.00548 \\
6 & 20.0 & 500 & 2 & 0.00576 \\
7 & 5.0 & 500 & 6 & 0.00524 \\
8 & 20.0 & 500 & 6 & 0.00613 \\
9 & 12.5 & 200 & 2 & 0.00482 \\
10 & 12.5 & 800 & 2 & 0.00539 \\
11 & 12.5 & 200 & 6 & 0.00559 \\
12 & 12.5 & 800 & 6 & 0.00501 \\
13 & 12.5 & 500 & 4 & 0.00466 \\
14 & 12.5 & 500 & 4 & 0.00479 \\
15 & 12.5 & 500 & 4 & 0.00470 \\
16 & 12.5 & 500 & 4 & 0.00475 \\
17 & 12.5 & 500 & 4 & 0.00494 \\
\hline
\end{tabular}

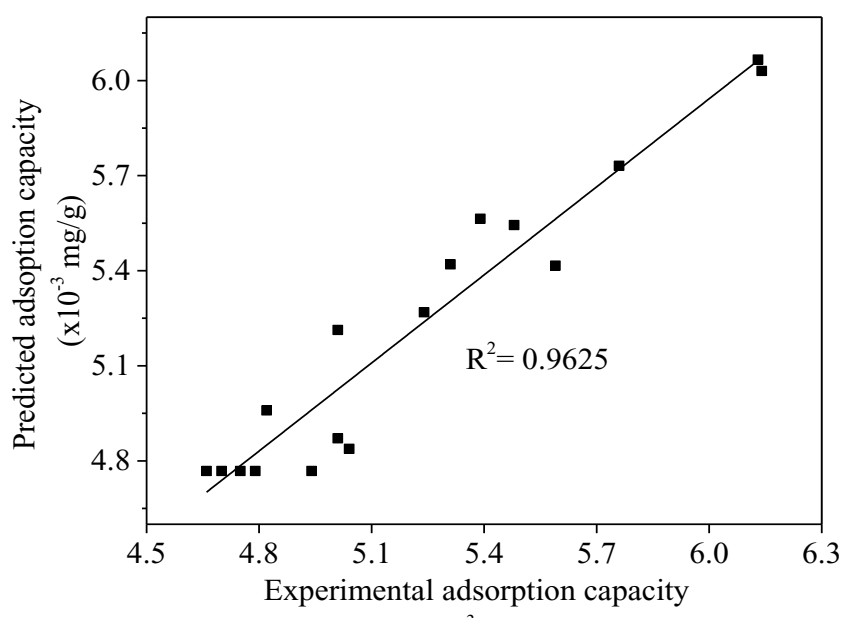

$\left(\mathrm{x} 10^{-3} \mathrm{mg} / \mathrm{g}\right)$

Fig. 1. Experimental and predicted values of $\mathrm{NO}$ adsorption capacity onto $\mathrm{CuO} / \mathrm{EFBC}$. 
For the model terms, Prob. $>\mathrm{F}$ less than 0.05 indicates that the model term is significant [15-16] and the largest F-value indicated that the model term has the most significant effect on the response [17]. Based on Table 3, the quadratic model for adsorption capacity has an $\mathrm{F}$-value of 16.24, indicating that this model is significant. In the case of model terms, $\mathrm{x}_{1}$, $\mathrm{x}_{1} \mathrm{X}_{2}, \mathrm{x}_{2} \mathrm{X}_{3}, \mathrm{x}_{1}{ }^{2}$ and $\mathrm{x}_{3}^{2}$ can be considered significant with Prob. $>\mathrm{F}$ values less than 0.05 . However, the rest of the model terms, $\mathrm{x}_{2}, \mathrm{x}_{3}, \mathrm{x}_{1} \mathrm{x}_{3}, \mathrm{x}_{2}{ }^{2}$ are insignificant to the adsorption capacity response. The model term which has the most significant effect on the response is $\mathrm{x}_{1}{ }^{2}$ with an F-value of 50.64 and the overall effects are in the order of $\mathrm{x}_{1}^{2}>\mathrm{x}_{3}^{2}>\mathrm{x}_{1} \mathrm{x}_{2}>\mathrm{x}_{1}>$ $\mathrm{x}_{2} \mathrm{X}_{3}$.

Based on the results in Table 3, it is also found that the combined effects due to interactions between metal loading and sintering temperature, as well as sintering temperature and sintering time are significant to the adsorption capacity. The effect of these model terms interactions on NO adsorption capacity are shown in graphical form in Figs. 2 (a) and 2(b) using three-dimensional response surface plots.

Fig. 2(a) shows that increasing metal loading from 5 to $20 \%$ (at a constant $200^{\circ} \mathrm{C}$ sintering temperature) enhances the adsorption capacity of NO from 0.00504 to 0.00614 $\mathrm{mg} / \mathrm{g}$. However, by keeping metal loading at $20 \%$, an increase in the sintering temperature decreases the adsorption capacity from 0.00614 to $0.00501 \mathrm{mg} / \mathrm{g}$. At the same metal loading of $5 \%$, decreasing the sintering temperature slightly reduces the adsorption capacity from 0.00531 to $0.00504 \mathrm{mg} / \mathrm{g}$. The interaction between high metal loading (20\%) and low sintering temperature $\left(200^{\circ} \mathrm{C}\right)$ appears to be more effective in enhancing NO adsorption capacity. This result is in agreement with the work done by Ryu et al. [18] which reported that as the metal loading increased, the adsorption capacity increased because the surface sites for reaction increased with the increase in metal loading. Zhu et al. [19] also reported similar finding to this work.

Table 3. ANOVA analysis of $\mathrm{NO}$ adsorption capacity by $\mathrm{CuO} / \mathrm{EFBC}$.

\begin{tabular}{llclll}
\hline Source & Sum of squares & Degree of freedom & Mean Square & F-Value & Prob. $>\mathrm{F}$ \\
\hline Model & $3.394 \times 10^{-6}$ & 9 & $3.771 \times 10^{-7}$ & 16.24 & 0.0006 \\
$\mathrm{x}_{1}$ & $4.851 \times 10^{-7}$ & 1 & $4.851 \times 10^{-7}$ & 20.89 & 0.0026 \\
$\mathrm{x}_{2}$ & $9.461 \times 10^{-8}$ & 1 & $9.461 \times 10^{-8}$ & 4.07 & 0.0833 \\
$\mathrm{x}_{3}$ & $3.380 \times 10^{-8}$ & 1 & $3.3800 \times 10^{-9}$ & 1.46 & 0.2668 \\
$\mathrm{x}_{1} \mathrm{X}_{2}$ & $4.900 \times 10^{-7}$ & 1 & $4.900 \times 10^{-7}$ & 21.10 & 0.0025 \\
$\mathrm{x}_{1}{ }_{3}$ & $9.302 \times 10^{-8}$ & 1 & $9.302 \times 10^{-8}$ & 4.01 & 0.0854 \\
$\mathrm{x}_{2} \mathrm{X}_{3}$ & $3.306 \times 10^{-7}$ & 1 & $3.306 \times 10^{-7}$ & 14.24 & 0.0070 \\
$\mathrm{x}_{1}{ }^{2}$ & $1.176 \times 10^{-6}$ & 1 & $1.176 \times 10^{-6}$ & 50.64 & 0.0002 \\
$\mathrm{x}_{2}{ }^{2}$ & $2.595 \times 10^{-8}$ & 1 & $2.595 \times 10^{-8}$ & 1.12 & 0.3256 \\
$\mathrm{x}_{3}{ }^{2}$ & $5.336 \times 10^{-7}$ & 1 & $5.336 \times 10^{-7}$ & 22.98 & 0.0020 \\
\hline
\end{tabular}

As can be observed in Fig. 2(b), at the same sintering time of $2 \mathrm{hrs,} \mathrm{decreasing} \mathrm{the}$ sintering temperature reduced the adsorption capacity from 0.00539 to $0.00482 \mathrm{mg} / \mathrm{g}$, while increasing sintering time from 2 to $6 \mathrm{hrs}$ (at a constant $200^{\circ} \mathrm{C}$ sintering temperature) increased the adsorption capacity of NO from 0.00482 to $0.00539 \mathrm{mg} / \mathrm{g}$. For a constant 6 hrs sintering time, higher temperature decreased the adsorption capacity from 0.00539 to $0.00501 \mathrm{mg} / \mathrm{g}$. Therefore, the interaction between high sintering time $(6 \mathrm{hrs})$ and low sintering temperature $\left(200^{\circ} \mathrm{C}\right)$ appears to be more effective in enhancing $\mathrm{NO}$ adsorption capacity. Prolonged sintering time is expected to allow impregnation of more catalyst on the surface of carbon. The impregnation of catalyst increased the catalytic activity, 
therefore resulted in higher adsorption capacity [20]. On the other hand, increasing the sintering temperature reduced the adsorption capacity because high sintering temperature destroys the activated carbon porous structures [21].
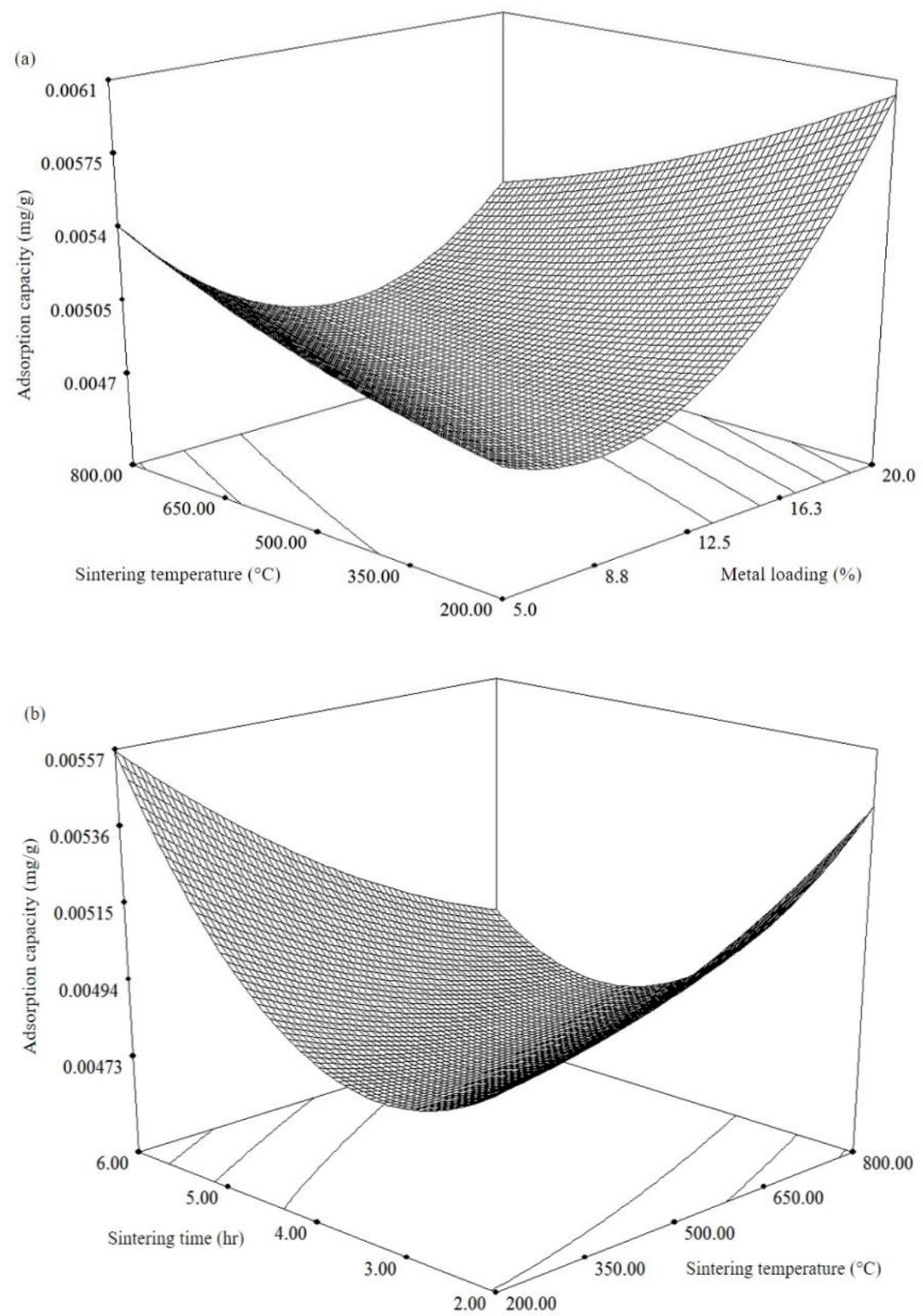

Fig. 2. Three-dimensional response surface plots of $\mathrm{NO}$ adsorption capacity by $\mathrm{CuO} / \mathrm{EFBC}$ due to: (a) interaction between sintering temperature and metal loading, while the sintering time was set constant at $4 \mathrm{hrs}$; and (b) interaction between sintering time and sintering temperature, while the metal loading was set constant at $12.5 \%$. 


\subsection{Model optimisation and validation}

Model optimisation was carried out over selected range of operating variables for $\mathrm{CuO}$ impregnation to obtain $\mathrm{CuO} / \mathrm{EFBC}$ with optimum $\mathrm{NO}$ adsorption capacity. By using Design-Expert software, a set of solution was generated by maximizing NO adsorption capacity and setting the individual variables, $\mathrm{x}_{1}, \mathrm{x}_{2}$ and $\mathrm{x}_{3}$. Based on our results and support from literature [20-21], it is known that higher metal loading and lower sintering temperature is significant for NO removal, while prolonged sintering time increases the catalytic active sites of catalyst for the removal of NO. Thus, to achieve maximum NO adsorption capacity. the variables goal of the experimental model were set to be maximum for metal loading whereas the sintering temperature and sintering time were set to be minimum and maximum respectively.

With the optimized variables condition i.e. $20 \%$ metal loading, $200^{\circ} \mathrm{C}$ sintering temperature and 6 hours sintering time, the model predicted an NO adsorption capacity of $0.00694 \mathrm{mg} / \mathrm{g}$, as shown in Table 4. Experimental validation of the NO adsorption capacity predicted by the model results in adsorption capacity of $0.00680 \mathrm{mg} / \mathrm{g}$, with only small error of $2 \%$. Therefore, the model and optimum operating variables developed can be considered valid and applicable for predicting the response.

Table 4. Model validation for activated carbon prepared for NO adsorption.

\begin{tabular}{llllllll}
\hline $\begin{array}{l}\text { Carbon } \\
\text { supported } \\
\text { catalyst }\end{array}$ & $\begin{array}{l}\text { Model } \\
\text { desirability }\end{array}$ & $\begin{array}{l}\text { Metal } \\
\text { Loading }\end{array}$ & $\begin{array}{l}\text { Sintering } \\
\text { temperature }\end{array}$ & $\begin{array}{l}\text { Sintering } \\
\text { time }\end{array}$ & \multicolumn{2}{l}{ NO adsorption capacity (mg/g) } \\
\cline { 7 - 9 } & & & & & & & \\
CuOdedicted & Experimental & Error \\
\hline
\end{tabular}

\section{Conclusions}

A quadratic model was developed using response surface methodology (RSM) with BoxBehnken Design for optimisation of selected $\mathrm{CuO}$ impregnation variables for enhancement of $\mathrm{NO}$ removal by $\mathrm{CuO} / \mathrm{EFBC}$. The model and variables i.e. metal loading, sintering time and sintering temperature of $\mathrm{CuO}$ impregnation was found to be significant in enhancing NO adsorption capacity (NO removal) through analysis of variance (ANOVA). The model term which has the most significant effect on the response is $\mathrm{x}_{1}{ }^{2}$ with an F-value of 50.64 and the overall effects are in the order of $x_{1}^{2}>x_{3}^{2}>x_{1} x_{2}>x_{1}>x_{2} x_{3}$. The interaction between high metal loading and low sintering temperature was noted to be most effective in enhancing NO adsorption capacity, followed by the interaction between high sintering time and low sintering temperature. The optimum operating variables for $\mathrm{CuO}$ impregnation onto EFBC at metal loading of $20 \%$, sintering temperature of $200^{\circ} \mathrm{C}$ and sintering time of 6 hours resulted in predicted NO adsorption capacity of $0.00694 \mathrm{mg} / \mathrm{g}$. Experimental validation of the NO adsorption capacity shows good agreement with the model prediction, with only $2 \%$ errors.

The authors would like to acknowledge the support from the Fundamental Research Grant Scheme (FRGS) under a grant number of FRGS/2/2013/SG01/UNIMAP/02/1 from the Ministry of Higher Education Malaysia. 


\section{References}

1. P. Nowicki, M. Skrzypczak, R. Pietrzak, Chem. Eng. J. 162, 2, 723 (2010).

2. S. Sumathi, S. Bhatia, K. T. Lee, A. R. Mohamed, Chem. Eng. J. 162, 1, 51 (2010).

3. X. Li, Z. Dong, J. Dou, J. Yu, A. Tahmasebi, Fuel Process. Technol. 148, 91 (2016).

4. N. Md-Desa, Z. Ab Ghani, S. Abdul-Talib, C. Tay, Malaysian J. Anal. Sci. 20, 3, 461 (2016).

5. I. Ghouma, M. Jeguirim, S. Dorge, L. Limousy, and A. Ouederni, C.R. Chim. 18, 2, 63 (2015).

6. O. A. Bereketidou, N. D. Charisiou, M. A. Goula, 13th International Conference of Environmental Science and Technology, Athens, Greece (2013).

7. J. M. Rosas, R. Ruiz-Rosas, J. Rodríguez-Mirasol, T. Cordero, Catal. Today 187, 1, 201 (2012).

8. P. Nowicki, H. Wachowska, R. Pietrzak, J. Hazard. Mater. 181, 1-3, 1088 (2010).

9. H. H. Tseng, C. Y. Lu, F. Y. Chang, M. Y. Wey, H. T. Cheng, Chem. Eng. J. 169, 1-3, 135 (2011).

10. N. Ahmad, N. Ibrahim, U. F. M. Ali, S. Y. Yusuf, F. M. Ridwan, Procedia Eng. 148, 823 (2016).

11. Z. Zhu, Z. Liu, S. Liu, H. Niu, T. Hu, T. Liu, Y. Xie, Appl. Catal. B 26, 25 (2000).

12. H. Tseng, M. Wey, Y. Liang, K. Chen, Carbon 41, 1079 (2003).

13. S. A. Pasma, R. Daik, M. Y. Maskat, O. Hassan, Int. J. Polym. Sci. 2013, 8 (2013).

14. Y. S. Mohammad, S. B. Igboro, A. Giwa, C. A. Okuofu, J. Eng. 2014, ID 278075 (2014).

15. M. Dutta, P. Ghosh, J. K. Basu, Appl. Sci. Res. 4, 2, 1053 (2012).

16. J. M. Salman, Arab. J. Chem. 7, 1, 10 (2014).

17. M. H. Kalavathy, I. Regupathi, M. Ganesa, L. Rose, Colloids Surf. B 70, 35 (2009).

18. S. K. Ryu, W. K. Lee, S. J. Park, D. D. Edie, Accessed online at url: http://acs.omnibooksonline.com/data/papers/2004_L008.pdf (2004).

19. Z. H. Zhu, L. R. Radovic, G. Q. Lu, Carbon 38, 3, 451 (2000).

20. G. Yang, Adv. Mater. Res., 428, 61 (2012).

21. K. H. Chuang, Z. S. Liu, M. Y. Wey, Mater. Sci. Eng. B, 175, 2, 100 (2010). 